\title{
Síndrome de Gorlin-Goltz. Diagnóstico molecular, nuevos tratamientos.
}

\author{
Gorlin-Goltz syndrome. Molecular \\ diagnosis, new treatments.
}

\author{
Sergio Olmedo-Cueva,* Mauricio Velasco Tizcareño, ${ }^{\ddagger}$ Hernán Castilla Canseco, ${ }^{\S}$ Fabiola Salgado-Chavarría ${ }^{\ddagger}$
}

\section{RESUMEN}

Introducción: El síndrome de Gorlin-Goltz o síndrome de carcinoma de nevo basocelular es un desorden hereditario autosómico dominante que predispone principalmente a la proliferación de múltiples carcinomas basocelulares, queratoquistes odontogénicos y defectos del desarrollo, causados por la mutación del gen Patched localizado en el cromosoma 9. Presentación del caso: Se reporta un paciente con características de este síndrome, en la clínica de COMF de la UNAM. El diagnóstico fue basado en los estudios clínicos, imagenológicos y moleculares. Conclusiones: El conocimiento de esta enfermedad puede orientarnos a la sospecha diagnóstica de lesión quística o premaligna en forma oportuna, lo que permite prevenir complicaciones y brindar un tratamiento integral para así mejorar la calidad de vida de este tipo de pacientes.

Palabras clave: Síndrome de Gorlin-Goltz, carcinomas basocelulares, queratoquistes, gen Patched 1.

\section{ABSTRACT}

Introduction: Gorlin-Goltz syndrome or cell-based nevus carcinoma syndrome is an autosomal dominant inherited disorder that predisposes mainly to the proliferation of multiple basal cell carcinomas, maxillary keratocysts and developmental defects, caused by the mutation of the Patched gene located on chromosome 9. Case presentation: A patient with specific characteristics compatible with this syndrome was reported in the COMF Department of the UNAM. The diagnosis was based on clinical studies, radiology and genetic studies. Conclusions: Knowledge of this problem can guide us to the diagnostic suspicion in a timely manner, thus preventing complications, and to provide an improved integral treatment of the quality of life of this type of patients.

Keywords: Gorlin-Goltz syndrome, basal cell carcinomas, keratocysts, Patched 1 gene.

\section{INTRODUCCIÓN}

$\mathrm{E}$ síndrome de Gorlin-Goltz fue reportado por primera vez en 1894 por Jarisch y White y descrito en 1960 por los autores a los que debe su nombre, Gorlin y Goltz. ${ }^{1}$ También es conocido como síndrome névico basocelular o síndrome del carcinoma nevoide basocelular. Inicialmente describieron la triada que caracteriza al síndrome: carcinomas basocelulares múltiples, que-

\footnotetext{
* Residente de cuarto año de la División de Estudios de Postgrado e Investigación (DEPeI), Consejo Mexicano de Cirugía Oral y Maxilofacial (COMF), UNAM.

‡ Docente adscrito a la DEPeI, COMF, UNAM.

$\S$ Médico de base del Hospital Pediátrico de Peralvillo.
}

Recibido: 18 Febrero 2020.

Aceptado para publicación: 30 Marzo 2020.

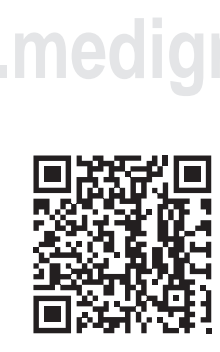

ratoquistes maxilo-mandibulares y costillas bífidas. Hoy se sabe que es una enfermedad genética de herencia autosómica dominante, penetrancia incompleta y fenotipo variable que predispone a la presencia de defectos del desarrollo y a la creación de neoplasias, entre los que destacan carcinomas basocelulares múltiples (CBC). ${ }^{2} \mathrm{La}$ patogenia molecular de este síndrome se ha relacionado con el gen Patched 1 (PTCH1), un gen supresor del tumor localizado en el cromosoma 9 (9q22, 3-q31), que codifica para el receptor transmembranal PTCH1, implicado en la vía de señalización Sonic hedgehog $(\mathrm{SHH}),{ }^{3,4}$ Hasta la fecha no se ha conseguido establecer una correlación entre el fenotipo y el genotipo de estos pacientes. $^{5}$

La identificación de la pérdida de funciónde mutaciones en PTCH1 en la mayoría de los CBC muestran un papel causal para este defecto genético en tumorogénesis. ${ }^{6}$ 
Su prevalencia estimada varía según las series publicadas, de entre $1 / 30,827^{7}$ y $1 / 256,000^{8}$ nacidos vivos. Farndon y colegas determinaron una prevalencia mínima de esta enfermedad de 1/57,000 habitantes, y estimaron que uno de cada 200 pacientes con uno o más CBC tienen SGG. ${ }^{9}$ La esperanza de vida de los enfermos de SGG es de 73.4 años, significativamente más reducida que la de la población general, que es de aproximadamente 80 años. ${ }^{10}$ La causa más importante de muerte prematura en estos pacientes es por meduloblastoma. ${ }^{11}$

El SGG es una enfermedad caracterizada clínicamente por la predisposición al desarrollo de múltiples neoplasias, así como por la aparición de anomalías en el desarrollo. El inicio de la clínica se produce en la infancia o adolescencia y se acompaña de la asociación de un conjunto de manifestaciones cutáneas, la más común es la presencia de numerosos carcinomas basocelulares, los cuales pueden afectar tanto en áreas fotoexpuestas como en no fotoexpuestas. Las localizaciones más frecuentes en hombres son el tercio superior de la espalda, las extremidades superiores y la zona medio facial; mientras que en las mujeres son el cuero cabelludo, la espalda y las extremidades inferiores. ${ }^{12}$

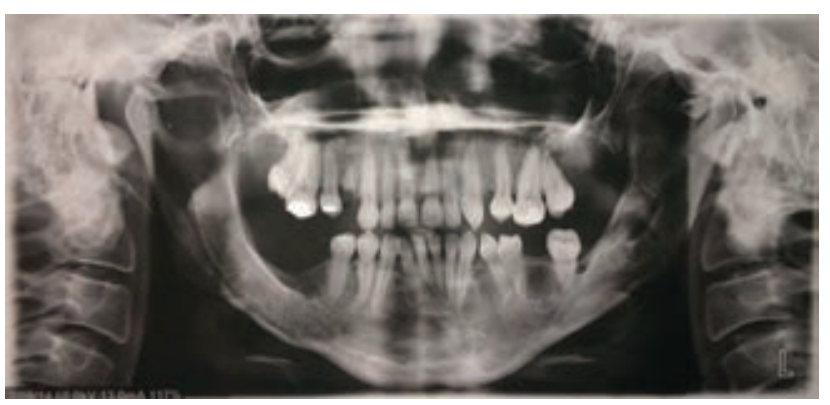

Figura 1: Ortopantomografía con quistes mandibulares de madre.

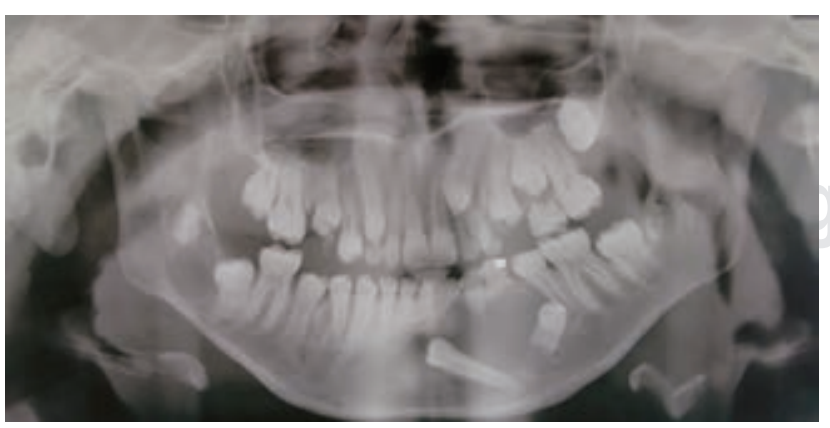

Figura 2: Ortopantomografía inicial.

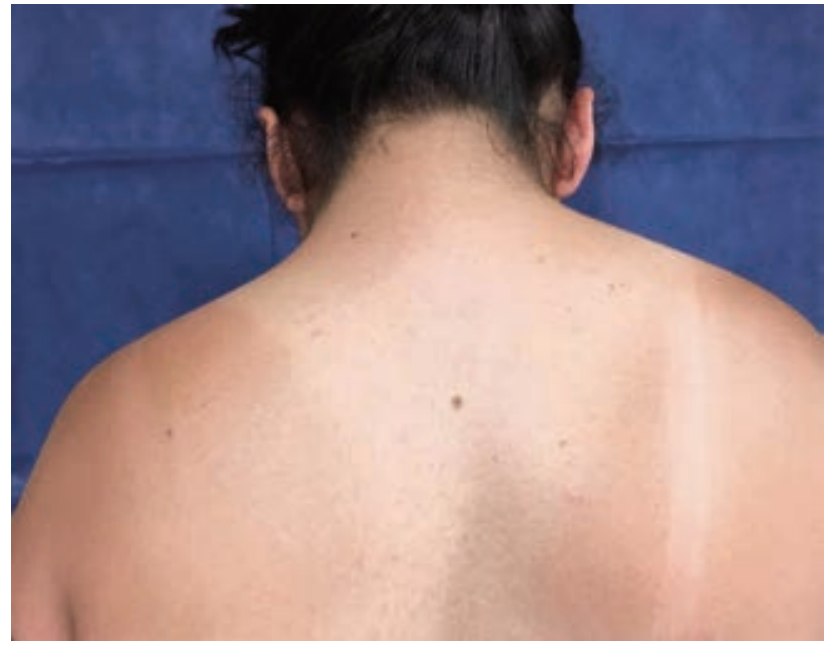

Figura 3: Signo de Sprengel.

\section{PRESENTACIÓN DEL CASO}

Se presenta paciente femenino de 12 años de edad a la Clínica de Cirugía Oral y Maxilofacial de la DEPel de la Facultad de Odontología de la UNAM, con aumento de volumen en región mandibular sinfisaria izquierda, asintomática, de aproximadamente 15 días de evolución, su madre refiere antecedentes de quistes mandibulares (Figura 1).

Se observó nevos en piel en la región periorbicular bilateral, por lo que se solicitó auxiliares diagnósticos como ortopantomografía; ésta mostró imágenes radiolúcidas asociadas con los dientes retenidos 33 y 34 de aproximadamente $35 \mathrm{~mm}$ en su diámetro mayor (Figura 2). A la palpación se apreció crepitación de la cortical vestibular, se llevó a cabo una punción exploratoria de la cual se obtuvo un contenido líquido amarillento, se realizó un extendido citológico que dio resultado compatible con contenido quístico, por lo cual se decidió la enucleación de la lesión con los dientes asociados a la misma, que a su análisis histopatológico mostró un resultado de tumor odontogénico queratoquístico. Los controles postoperatorios tuvieron una evolución favorable. Nueve meses después se tomó una tomografía en la que se mostraron imágenes hiperdensas asociadas al tercer molar inferior derecho, motivo por el cual se solicitó estudios especializados y junto con el análisis clínico se observaron pits en palmas de manos y plantas de pies y el signo de Sprengel positivo (Figura 3).

Se recabaron estudios de imagen complementarios como radiografías craneales, posteroanterior y lateral, en las que se pudo observar imágenes compatibles con 


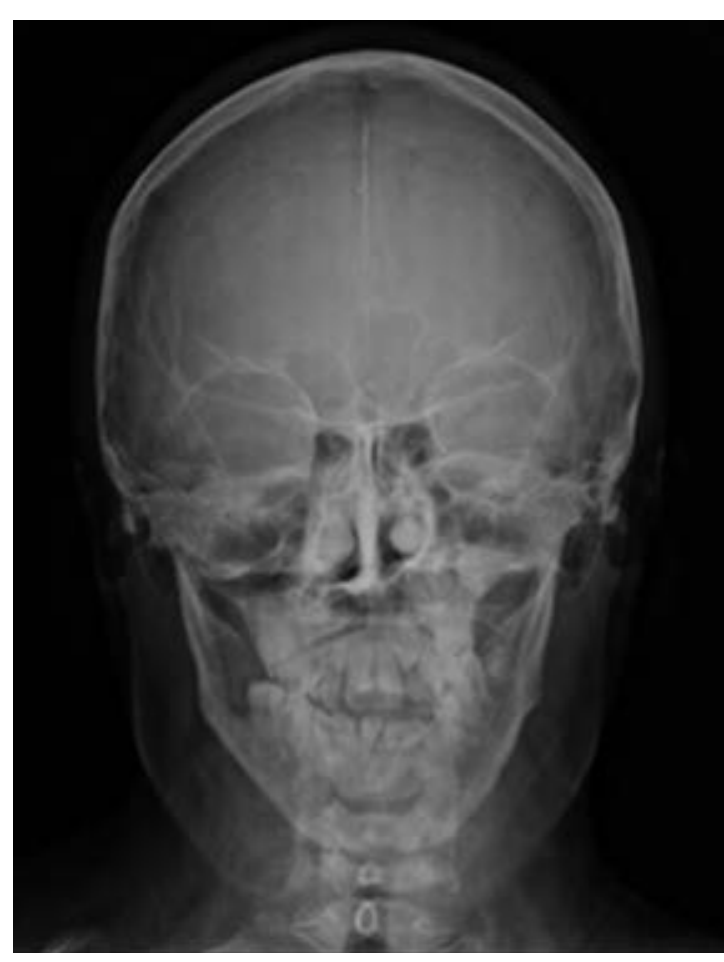

Figura 4: Radiografía posteroanterior que muestra la calcificación de la hoz del cerebro.

calcificación de la hoz del cerebro (Figura 4), fusión de la silla turca y en una telerradiografía de tórax se observó el cuarto arco costal derecho fusionado (Figura 5).

Todos estos estudios son evidencia clínica e imagenológica que la convierte en candidata idónea para diagnosticar el SGG, puesto que cumple con criterios mayores y menores. Para su análisis molecular se solicitó estudio genético tanto a la madre como a la paciente, en los cuales no se observó alteración del receptor transmembranal PTCH1 en ninguno de los casos. Posteriormente, a los 12 meses, se tomó una biopsia excisional de la lesión asociada al diente 48 que dio como resultado queratoquiste odontogénico (Figura 6).

En las imágenes de control a los seis meses se mostró adecuada aposición ósea, agregado a estos cambios se pudo constatar imágenes radiolúcidas en región de tuberosidad maxilar de forma bilateral y en región mandibular asociada al diente 38. Se decidió la enucleación de las posibles lesiones quísticas, con osteotomías periféricas de $2 \mathrm{~mm}$ aproximadamente, más la aplicación de 5 fluorouracilo (5FU) aplicado con una gasa en el lecho quirúrgico y retirada a las 24 horas; en el mismo tiempo quirúrgico se llevó a cabo la biopsia excisional de nevos en región periorbicular izquierda, que dio como resultado, al estudio histopatológico, un carcinoma basocelular sólido (Figura 7).

En la actualidad, a los cuatro años de seguimiento, se observa adecuada cicatrización de heridas faciales e imagenológicamente se muestra reposición ósea sin datos de recurrencia de entidades quísticas (Figuras $8 A$ y B).

\section{DISCUSIÓN}

La patogenia molecular de este síndrome se ha relacionado con el gen Patched 1 (PTCH1), un gen supresor del tumor localizado en el cromosoma 9 (9q22, 3-q31), que

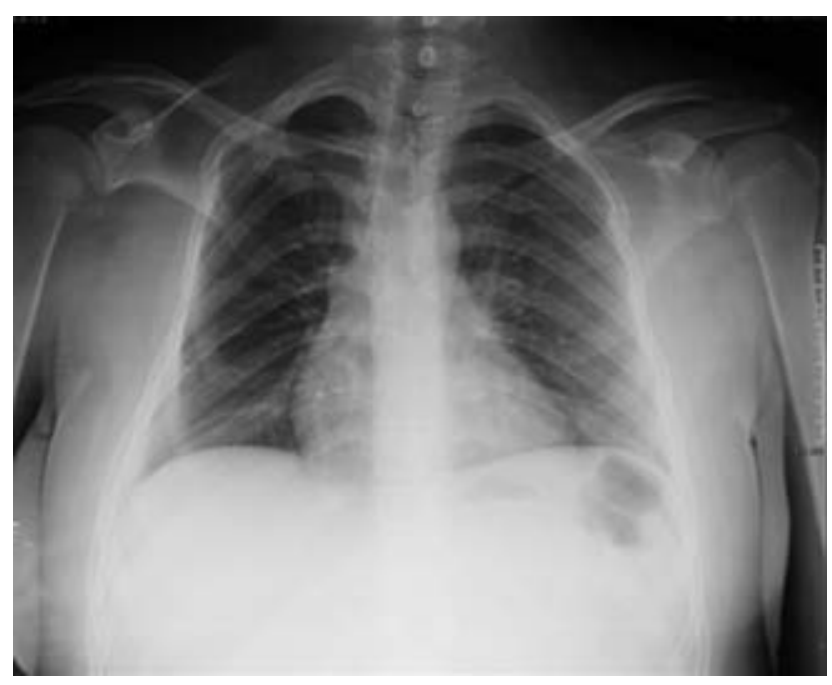

Figura 5: Telerradiografía de tórax con quinto arco costal derecho fusionado.

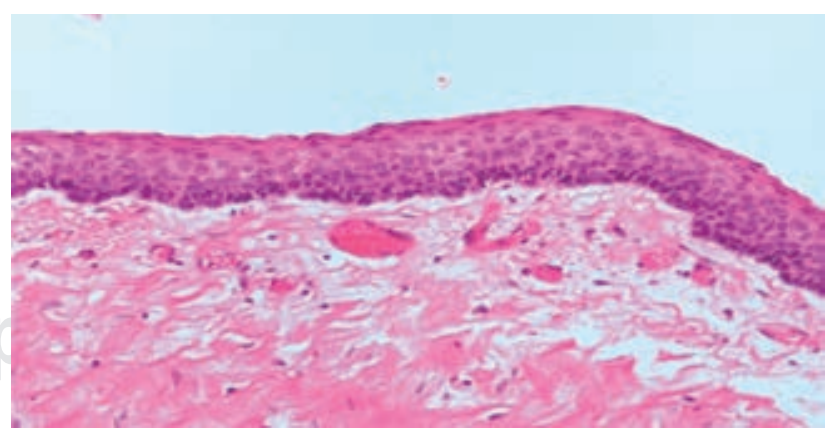

Figura 6: Se observa en esta microfotografía teñida con E y H un epitelio escamoso estratificado paraqueratinizado, de 6 a 8 capas celulares de grosor, con núcleos del estrato basal dispuestos en empalizada que recubre tejido conjuntivo denso. 


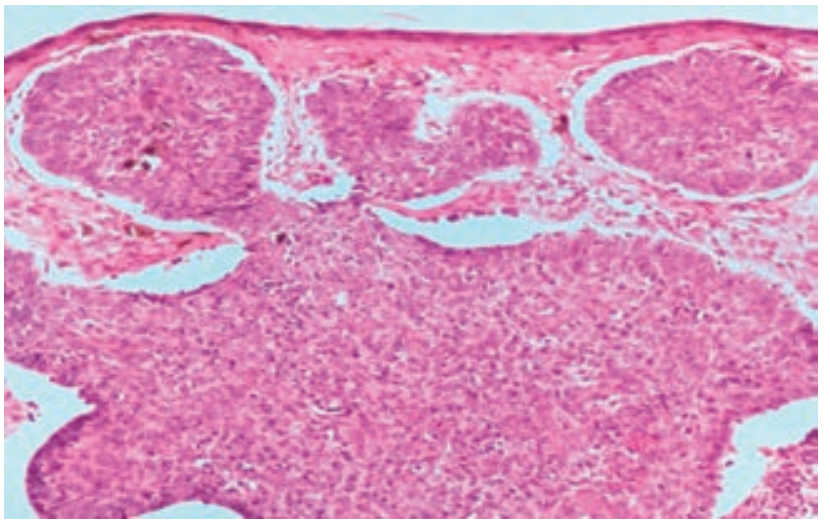

Figura 7: Se muestra en esta microfotografía teñida con E y H la presencia de células neoplásicas de morfología oval, algunas ahusadas y algunas con cromatina dispersa, algunos núcleos hipercromáticos.

codifica para el receptor transmembranal PTCH1, implicado en la vía de señalización Sonic hedgehog $(\mathrm{SHH}){ }^{3,4}$ En nuestro caso, la prueba molecular para este gen fue negativa en la paciente y en su progenitora. Esto se explica porque el gen PTCH1 está alterado en $65 \%$ de los casos, es decir, pueden estar alterados otros componentes de la vía SHH como: PTCH 2, SUFU, GLI, SMOTH. ${ }^{13}$

Evans y colaboradores primero establecieron criterios mayores y menores para el diagnóstico del síndrome y luego fueron modificados por Kimonis y su equipo en $2004 .^{14}$

Para el diagnóstico del síndrome es necesario que se cumplan dos criterios mayores, o uno mayor y dos menores. Bree y colaboradores, en 2011, publicaron un documento de consenso con nuevos criterios diagnósticos en el que se incluyó por primera vez el estudio molecular (Tabla 1). ${ }^{12}$ Este estudio genético se recomienda reservarlo para tres escenarios: primero, en el diagnóstico prenatal si se conoce la mutación en la familia; segundo, para un diagnóstico de confirmación en pacientes que presentan algunos signos de enfermedad pero no cumplen los criterios diagnósticos; y tercero, como prueba predictiva en individuos con riesgo de presentar la enfermedad y que no cumplen los criterios diagnósticos pero tienen un familiar afectado. ${ }^{12}$

Las manifestaciones incluyen pits palmoplantares, se encuentran entre 70 y $87 \%$ de los pacientes, se presentan como depresiones puntiformes de 2-3 mm de diámetro que aparecen en las palmas de las manos, en las plantas de los pies y raramente en los dorsos laterales de los dedos y pliegues interdigitales. ${ }^{15}$ En el presente caso se muestran pits en las palmas de las manos, pero no en las plantas de los pies.
Dentro de las manifestaciones extracutáneas con respecto a anomalías en el desarrollo encontramos a los queratoquistes odontogénicos, asintomáticos múltiples y con localización en ambos lados de la mandíbula. ${ }^{11}$ En nuestro caso, se presentaron múltiples queratoquistes: tres mandibulares y dos maxilares que recibieron manejo clínico-quirúrgico. Los queratoquistes odontogénicos se presentan entre 74 y $90 \%$ de los pacientes con SGG. ${ }^{5}$

Otros signos incluyen: anomalías esqueléticas, alteraciones no tumorales del sistema nervioso central y la más frecuente es la calcificación de la hoz del cerebro, presente en $65-79 \%$ del síndrome. ${ }^{5,12,15-18}$ Nosotros encontramos que la paciente tiene presente este signo.

Rara vez se muestra calcificación de la tienda del cerebelo, específicamente del ligamento petroclinoide y del diafragma sellar. ${ }^{19}$ Nuestra paciente presentó la calcificación de los ligamentos interclinoideos, poniéndose en manifiesto este dato clínico.

Se ha detectado macrocefalia relativa e hipertelorismo, ${ }^{15}$ asociado en muchos casos con telecanto. Además del hipertelorismo se ha notificado una mayor prevalencia de exoftalmo, nistagmo rotatorio, estrabismo interno, cataratas congénitas, coloboma del iris y coroides, y
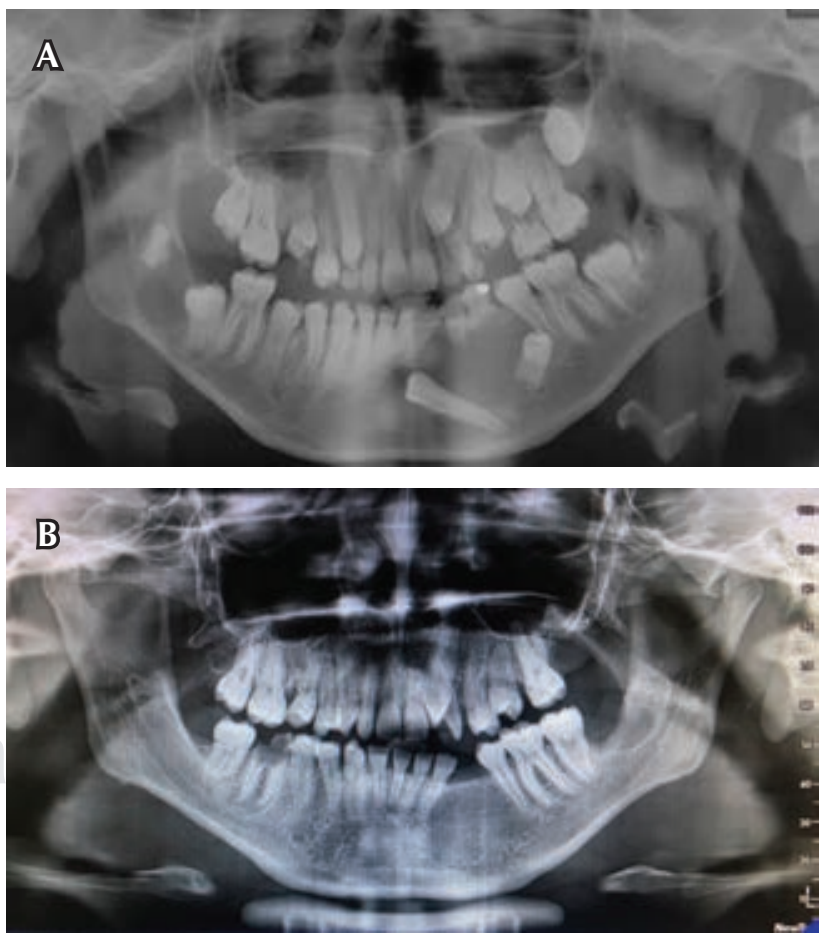

Figura 8: A) Ortopantomografía inicial abril de 2016. B) Ortopantomografía marzo de 2020. 


\section{Tabla 1: Criterios diagnósticos del síndrome de Gorlin-Goltz.}

Criterios mayores

- $\mathrm{CBC}$ en $<20$ años o número excesivo de $\mathrm{CBC}$ para la exposición solar o fototipo

- Queratoquistes en maxilares comprobados por histopatología

- Pits palmoplantares

- Calcificación lamelar de la hoz cerebral

- Meduloblastoma

- Familiar de primer grado con SGG

- Otras anormalidades esqueléticas y cambios radiográficos (anormalidades vertebrales, cifoescoliosis, cuarto metacarpiano corto, polidactilia)

- Confirmación molecular
Criterios menores

- Anomalías costales

- Macrocefalia

- Fibromas ováricos o cardiacos

- Anomalías oculares (estrabismo, hipertelorismo, catarata congénita, glaucoma, coloboma)

- Labio o paladar hendido

- Quistes lifomesodérmicos microftalmia. ${ }^{7}$ Esta paciente presenta macrocefalia, hipertelorismo y estrabismo interno.

Entre las anomalías otológicas destacan otosclerosis, sordera de conducción y angulamiento posterior de los pabellones auriculares. ${ }^{20}$ Los cuales no se manifestaron en nuestro caso.

Existen también alteraciones en vértebras, costillas y escápula, de $38-49 \%{ }^{9}$ muestran costillas bífidas ${ }^{15}$ o costillas separadas, fusionadas, ausentes, costillas cervicales y costillas rudimentarias. El cuarto arco costal derecho y fusión vertebral cervical están presentes en nuestra paciente.

De 1-5\% de los pacientes con SGG desarrollan tumores no cutáneos como meduloblastomas malignos, 5,12,15-18 fibromas cardiacos y ováricos, ${ }^{5}$ que aunque son infrecuentes pueden presentarse, al igual que otros tumores como meningiomas en un 5\% de estos pacientes. Ninguno de estos se encontró en el caso.

A pesar de las altas tasas de curación de las lesiones individuales y las diversas modalidades de tratamiento, incluida la excisión, la cirugía micrográfica de Mohs, la terapia fotodinámica y el imiquimod tópico, el manejo de los CBC es un desafío. ${ }^{21}$

La aplicación tópica de 0,1\% de 5-fluoracilo o la aplicación intralesional de interferón alfa 2 b han sido otras propuestas terapeúticas. $^{22}$

Nuestro manejo del los CBC en cara fue realizado mediante excisión quirurgica, complementada con la aplicación de 5-fluoracilo tópico y la recomendación de uso de pantallas solares cada 4 horas.

Las posibilidades terapéuticas de estos pacientes han avanzado recientemente con la introducción del inhibidor de $\mathrm{SHH}$ vismodegib, indicado en el tratamiento de CBC metastásico recurrente localmente avanzado, mismo que en nuestro caso se reportó como CBC sólido.

Los queratoquistes pueden tratarse por medio de la enucleación quística, marsupialización y se recomienda la cauterización química después de la enucleación con solución de Carnoy que es un compuesto fenólico para evitar la reincidencia. ${ }^{23} \mathrm{O}$ bien, el uso de inhibidores de la vía de señalización SHH como el 5-fluorouracilo (5FU).

\section{CONCLUSIONES}

El SGG es una enfermedad de herencia autosómica dominante debida a mutaciones a nivel molecular que está presente entre 60 y $80 \%$ de los casos. De no expresarse esta alteración, el estudio molecular debe ir encaminado a la supresión de cualquiera de los componentes de la vía de señalización, que al mostrarse suprimidos muestran diversas alteraciones vistas en el síndrome.

Se debe mantener un equipo multidisciplinario para el diagnóstico, seguimiento y manejo de estos pacientes.

El diagnóstico oportuno del síndrome traerá consigo un adecuado protocolo de tratamiento, que de ser acertado mejorará sustancialmente el pronóstico, que en ciertos casos puede llegar a ser fatal.

\section{BIBLIOGRAFÍA}

1. Gorlin RJ, Goltz RW. Multiple nevoid basal cell epithelioma, jaw cyst and bifid rib. A syndrome. N Engl J Med. 1960; 262: 908-912.

2. Gorlin R. Nevoid basal cell carcinoma syndrome. Medicine (Baltimore). 1987; 66: 98-113.

3. Hahn H, Wicking C, Zaphiropoulous P, Gailani M, Shanley S, Chidambaram A. Mutations of the human homolog of Drosophila 
patched in the nevoid basal cell carcinoma syndrome. Cell. 1996; 85: 841-851.

4. Epstein EH. Basal cell carcinomas: attack of the hedgehog. Nat Rev Cancer. 2008; 8: 743-754.

5. Evans D, Farndon P. Nevoid basal cell carcinoma syndrome. In: Pagon RA, Adam MP, Ardinger HH, Wallace SE, Amemiya A, BeanLJH et al., editors. Gene reviews [Internet]. Seattle (WA): University of Washington, Seattle; 1993-2015 [actualización 1 Oct 2015].

6. Wong SY, Dlugosz AA. Basal cell carcinoma. Hedgehog signaling, and targeted therapeutics: the long and winding road. J Invest Dermatol. 2014; 134: E18-E22.

7. Evans DG, Howard E, Giblin C, Clancy T, Spencer H, Huson SM et al. Birth incidence and prevalence of tumor-prone syndromes: estimates from a UK family genetic register service. Am JMed Genet A. 2010 ; 152A: 327-332.

8. Lo Muzio L, Pastorino L, Levanat S, Musani V, Situm M, Ponti G et al. Clinical utility gene card for: Gorlin syndrome update 2013. Eur J Hum Genet. 2013; 21: 1-3.

9. Farndon PA, del Mastro RG, Evans DG, Kilpatrick MW. Location of gene for Gorlin syndrome. Lancet. 1992; 339: 581-582.

10. Wilding A, Ingham SL, Lalloo F, Clancy T, Huson SM, Moran A et al. Life expectancy in hereditary cancer predisposing diseases: an observational study. J Med Genet. 2012; 49: 264-269.

11. Lo Muzio L. Nevoid basal cell carcinoma syndrome (Gorlin syndrome). Orphanet J Rare Dis. 2008; 3: 32.

12. Tom WL, Hurley MY, Oliver DS, Shah MR, Bree AF. Features of basal cell carcinomas in basal cell nevus syndrome. Am J Med Genet A. 2011; 155A: 2098-2104.

13. Akbari M, Chen H, Guo G, Legan Z, Ghali G. Basal cell nevus syndrome (Gorlin syndrome): genetic insights, diagnostic challenges, and unmet milestones. Pathophysiology. 2018; 25 (2): 77-82.

14. Joshi PS, Deshmukh V, Golgire S. Gorlin-Goltz syndrome. Dent Res J. $2012 ; 9$ (1): 100-106.
15. Kimonis VE, Goldstein AM, Pastakia B, Yang ML, Kase R, DiGiovanna $\mathrm{JJ}$ et al. Clinical manifestations in 105 persons with nevoid basal cell carcinoma syndrome. Am J Med Genet. 1997; 69: 299-308.

16. Wallace DL, Jaffe W. Reply to: do basal cell carcinomas recur after complete conventional surgical excision? R.W. Griffiths, S.K., Suvarna. J Stone BJPS. 2005;58:795-805. J Plast Reconstr Aesthet Surg. 2006; 59: 1247.

17. Jones JEA, Sajid MI, Shenton A, Evans DG. Basal cell carcinomas in Gorlin syndrome: a review of 202 patients. J Skin Cancer. 2011; 2011: 217378.

18. Bree AF, Shah MR, BCNS Colloquium Group. Consensus statement from the first international colloquium on basal cell nevus syndrome (BCNS). Am J Med Genet A. 2011; 155A: 2091-2097.

19. Ratcliffe J, Shanley S, Ferguson J, Chenevix Trench G. The diagnostic implication of falcine calcification on plain skull radiographs of patients with basal cell naevus syndrome and the incidence of falcine calcification in their relatives and two control groups. Br J Radiol. 1995; 68: 361-368.

20. Kiwilsza M, Sporniak-Tutak K. Gorlin Goltz syndrome - a medical condition requiring a multidisciplinary approach. Med Sci Monit. 2012; 18: RA145-RA153.

21. Lam C, Ou JC, Billingsley EM. PTCH-ing it together: A basal cell nevus syndrome review. Dermatol Surg. 2013; 39: 1557-1572.

22. Rosón-Gómez S, González-García R, Naval-Gías L, Sastre-Pérez J, Muñoz-Guerra MF, Díaz-González FJ. Síndrome de Gorlin-Goltz: serie de 7 casos. Rev Esp Cirug Oral y Maxilofac. 2009; 31 (5): 309-315.

23. Escamilla OC, Sánchez LR, Sánchez GL, Treviño AM, Martínez MH, Rivera SG. Síndrome de Gorlin-Goltz reporte de un caso clínico. Rev ADM. 2013; 70 (1): 43-45.

\section{Correspondencia:}

Fabiola Salgado-Chavarría

E-mail: cmf_fabiolasalgado@hotmail.com 